\title{
Modeling and Control of Irrigation Systems: A Short Survey and Future Directions
}

\author{
${ }^{1}$ Meriç Çetin and ${ }^{* 2}$ Selami Beyhan \\ ${ }^{1}$ Faculty of Engineering, Computer Engineering, Pamukkale University, Kinikli,20070 Denizli, Turkey. (e-mail: \\ mcetin@pau.edu.tr). \\ ${ }^{*}$ Faculty of Engineering, Electrical and Electronics Engineering, Izmir Democracy University, Uckuyular District, \\ Gursel Aksel Blv., 35140, Karabaglar, Izmir, Turkey. (e-mail: selami.beyhan@idu.edu.tr).
}

\begin{abstract}
Modeling and control of irrigation systems has importance for the yield of the crops and especially, saving the water sources has prominent importance for the world. In this paper, recent modeling and control methods for the irrigation systems are surveyed for the future applications. Even though a mathematical model is constructed for the amount of water in soil, there are too many unpredictable disturbances on the irrigation systems so that the mathematical model cannot be exact. Therefore, the accuracy of the literature control methods is less than expected results. As a solution, the unknown model-based control methods and also accurate prediction methods are going to be promising approaches for irrigation systems in future.
\end{abstract}

Key words: irrigation models, control methods, yield of the crops, water source.

\section{Modeling of Irrigation Systems}

At the beginning, detailed models for the water content of the soil is formulized by different functions of the temperature, evapotranspiration, radiation, pressure and etc. [1]. In order to control the irrigation system over a continuous-time model, a system engineering model is developed based on the system identification theory [2]. The parameters of the continuous-time model are accurately estimated by optimization methods thus the proposed model is accepted as a base model for future control applications.

The given mathematical model is a first-order auto-regressive model, introduced in [2-5], was used to describe the water balance in the soil of the root zone. Both inflows (irrigation and precipitation) and outflows (evapotranspiration, runoff and deep percolation) determine the amount of water in the soil. Accordingly, system identification based mathematical model is as follows.

$$
x_{\mathrm{t}+1}=(1-c) x_{\mathrm{t}}+u_{\mathrm{t}}+p_{\mathrm{t}}-e_{\mathrm{t}}
$$

where $x_{\mathrm{t}}$ and $u_{\mathrm{t}}$ are amount of the water in soil and irrigation amount in time-period, respectively. $e_{\mathrm{t}}$ is the cumulative evapotranspiration and $p_{\mathrm{t}}$ is the precipitation. In this model, water flow and water percolation are assumed to be proportional to soil moisture. The decay factor (c) which can be determined by system identification techniques is modeled in the

*Corresponding author: Address: Faculty of Engineering, Electrical and Electronics Engineering, Izmir Democracy University, Uckuyular District,Gursel Aksel Blv., 35140, Karabaglar, Izmir, Turkey. (e-mail: selami.beyhan@idu.edu.tr). 
range $0<c<1$.

\section{Control of Irrigation Systems}

As water resources become limited, the use of water in semi-arid or arid areas for agricultural applications needs to be more effectively controlled. Due to differences in soil characteristics and water availability, evolving irrigation management specific to variable conditions improve the efficiency and reduce dependence on environmental impacts [8]. Irrigation control systems adapted to variable cases are used in central pivot systems that provide optimal water supply according to needs [7].

In recent years, the applicability of computerized control for irrigation system in agriculture has increased remarkably. There are many studies with irrigation systems in the literature. For example, decision support systems have been used for water conservation and maximizing yield in irrigation systems [6]. A daily plan model to the irrigation of a crop field using optimal control was developed in [9]. In [5, 10-12], a data-driven model predictive controller was proposed for automatic control of irrigation systems. However, conventional methods such as on-off or proportional control methods are not effective due to energy loss and productivity [13]. In contrast, an irrigation model can be developed with the fuzzy logic controller taking into account the factors affecting irrigation. In [14], a solution has been proposed for an irrigation controller based on fuzzy logic methodology. In [15], the integration of fuzzy logic and real-world irrigation planning problems was examined. A fuzzy logic based weather dependent irrigation control mechanism was proposed in [16]. The fuzzy logic controller provides an effective approach, especially if we do not have complete knowledge of the system or if precise control is required [17]. In the literature, there are also designs of precision irrigation systems using computer controlled and wireless transmission technology [18-20].

\section{Applied Control Methods}

Nonlinear adaptive controllers, which based on the feedback linearization rule, are used to control nonlinear systems in diverse areas [21]. Using by this approach, a nonlinear control problem becomes a linear control problem [22]. There are two different approaches in the design of fuzzy adaptive control system: direct and indirect. The direct method uses a fuzzy system to define the control action and the parameters of the fuzzy system are set directly. In the indirect adaptive approach, fuzzy systems are used to estimate the plant dynamics. Then, a control law based on these estimates is synthesized.

\subsection{Fuzzy Control}

A fuzzy system consists of a set of IF-THEN type rule bases, each of which has an antecedent and consequent parts [21, 22]. These rule bases have rules to indicate the systems input-output relations. Rules are constructed with linguistic propositions, which have linguistic variables and linguistic values. In fuzzy systems, these linguistic values are represented with membership functions. So they are the basic and essential element of the rule base. A fuzzy rule-base consists 
of $\mathrm{M}$ rules is represented as

$R_{1}$ : IF $x_{1}$ is $A_{1}^{l}$ and $x_{2}$ is $A_{2}^{l}$ and ... and $x_{n}$ is $A_{n}^{l}$ THEN $y^{l}$ is $B^{l}$

where $l=1,2, \ldots M$ is the number of the rules, $x_{i}(i=1,2, \ldots, n)$ are the inputs to fuzzy system, $y$ is output variable, $A_{i}^{l}, B_{i}^{l}$ are linguistic values which are represented by membership functions. A fuzzy control input can be represented as a non-orthogonal expansion using input membership functions [23] as

$$
\mathrm{u}(\mathrm{x})=\frac{\sum_{\mathrm{l}=1}^{\mathrm{M}} \mathrm{y}^{\mathrm{l}}\left(\prod_{\mathrm{i}=1}^{\mathrm{n}} \mu_{\mathrm{A}_{\mathrm{i}}^{\mathrm{l}}}\left(\mathrm{x}_{\mathrm{i}}\right)\right)}{\sum_{\mathrm{l}=1}^{\mathrm{M}}\left(\prod_{\mathrm{i}=1}^{\mathrm{n}} \mu_{\mathrm{A}_{\mathrm{i}}^{\mathrm{l}}}\left(\mathrm{x}_{\mathrm{i}}\right)\right)}
$$

where $y_{l}$ are constants or output weights. $\mu_{A_{i}^{l}}\left(x_{i}\right)$ are the membership functions of the inputs such as Gaussian, triangle, bell shaped and etc. The fuzzy model is formed using singleton fuzzifier, product inference, centroid defuzzifier and membership function [15]. $u(x)$ and $y($.$) in$ the fuzzy controller are the input/output values that define the amount of irrigation and water in the soil as given in Eq. (1).

\subsection{Proportional-Integral-Derivative (PID) Control}

Conventional PID controllers are still preferred in industrial applications due to the simplicity of design, efficiency, functionality, applicability and ease of use. A conventional PID controller is also known as a controller whose transfer function is usually written in "parallel form" as follows [24]

$$
\mathrm{G}(\mathrm{s})=\mathrm{K}_{\mathrm{P}}+\mathrm{K}_{\mathrm{I}} \frac{1}{\mathrm{~s}}+\mathrm{K}_{\mathrm{D}} \mathrm{s}
$$

The proportional gain $\left(\mathrm{K}_{\mathrm{P}}\right)$ - providing an overall control action proportional to the error signal through the all-pass gain factor. The integral term $\left(\mathrm{K}_{\mathrm{I}}\right)$ - reducing steady-state errors through low-frequency compensation by an integrator. The derivative term $\left(\mathrm{K}_{\mathrm{D}}\right)$-improving transient response through high-frequency compensation by a differentiator [25]. The conventional PID controller formula is given as

$$
u(t)=K_{P} e(t)+K_{I} \int_{0}^{\tau} e(t) d t+K_{D} \frac{d}{d t} e(t)
$$

where $e(t)=r(t)-y(t)$ and $r(t)$ is the reference signal or set-point. $u(t)$ and $y(t)$ in the PID controller are the input/output values that indicate the amount of irrigation and water in the soil as given in Eq. (1).

\subsection{Model Predictive Control}

In general nonlinear, continuous-time, multi-input multi-output nonlinear system dynamics are described in closed form as [5] 


$$
\begin{aligned}
& \dot{x}=f(x, u), \\
& y=g(x, u), \\
& u \in U, x \in \quad X, \forall t \geq 0 .
\end{aligned}
$$

where $\mathrm{x}(\mathrm{t}) \in \mathfrak{R}^{\mathrm{N}}$ is the state vector, $\mathrm{u}(\mathrm{t}) \in \mathfrak{R}^{\mathrm{R}}$ is the input vector and $\mathrm{y}(\mathrm{t}) \in \mathfrak{R}^{\mathrm{Q}}$ is the output vector. It is assumed that the nonlinear system (6) is controllable, the functions of process and measurements are known and they can be derived from states, parameters and input signal of the system. The states and output signals are iterated after applying the control signals, which is produced by the controller that is designed for the conditions of which only system inputs and outputs are measurable. The discrete-time values of the dynamics can be obtained by using integration methods. There are plenty of discretization methods that have been used to obtain a discrete-time model of a nonlinear system in literature. Due to its superior characteristics as correction and stability, the fourth-order Runge-Kutta (RK) discretization method has been used to obtain the discrete-time model of the continuous-time nonlinear system. If the states are $\mathrm{x}_{1}[\mathrm{n}], \cdots, \mathrm{x}_{\mathrm{N}}[\mathrm{n}]$ and inputs are $\mathrm{u}_{1}[\mathrm{n}], \cdots, \mathrm{u}_{\mathrm{R}}[\mathrm{n}]$ with a time index $\mathrm{n}$ for a MIMO system (6), the predicted state and output vectors for the next sampling period can be written as

$$
\begin{aligned}
x[n+1] & =\hat{f}(x[n], u[n]) \\
& =x[n]+\frac{1}{6}\left(k_{1}+2 k_{2}+2 k_{3}+k_{4}\right), \\
\hat{y}[n+1] & =g(x[n], u[n]),
\end{aligned}
$$

where the integration components

$$
\begin{aligned}
& \mathrm{k}_{1}=\mathrm{T}_{\mathrm{s}} \hat{\mathrm{f}}(\mathrm{x}[\mathrm{n}], \mathrm{u}[\mathrm{n}]) \\
& \mathrm{k}_{2}=\mathrm{T}_{\mathrm{s}} \hat{\mathrm{f}}\left(\mathrm{x}[\mathrm{n}]+0.5 \mathrm{k}_{1}, \mathrm{u}[\mathrm{n}]\right) \\
& \mathrm{k}_{3}=\mathrm{T}_{\mathrm{s}} \hat{\mathrm{f}}\left(\mathrm{x}[\mathrm{n}]+0.5 \mathrm{k}_{2}, \mathrm{u}[\mathrm{n}]\right) \\
& \mathrm{k}_{4}=\mathrm{T}_{\mathrm{s}} \hat{\mathrm{f}}\left(\mathrm{x}[\mathrm{n}]+\mathrm{k}_{3}, \mathrm{u}[\mathrm{n}]\right) .
\end{aligned}
$$

The function $\hat{f}$ defined in (7) expresses the discrete-time model of a nonlinear continuous-time system with a very small approximation error. In MPC structure, the discrete-time model $\hat{\mathrm{f}}$ produces the future predictions of the system corresponding to the vector of the candidate control signal. $\left[\hat{y}_{1}[n+1], \ldots, \hat{y}_{q}\left[n+K_{y}\right]\right]$ is the prediction vector of the $q^{\text {th }}$ output for $K_{y}$-step after, where $\mathrm{K}_{\mathrm{y}}$ is the prediction horizon. The prediction error e can be written as

$$
\mathrm{e}=\left[\begin{array}{c}
\overline{\mathrm{y}}_{1}[\mathrm{n}+1]-\hat{\mathrm{y}}_{1}[\mathrm{n}+1] \\
\overline{\mathrm{y}}_{\mathrm{Q}}\left[\mathrm{n}+\mathrm{K}_{\mathrm{y}}\right]-\hat{\mathrm{y}}_{\mathrm{Q}}\left[\mathrm{n}+\mathrm{K}_{\mathrm{y}}\right] \\
{\sqrt{\lambda_{1}} \Delta \mathrm{u}[\mathrm{n}]}^{\vdots} \\
\sqrt{\lambda}_{\mathrm{R}} \Delta \mathrm{u}[\mathrm{n}]
\end{array}\right]_{(\mathrm{QK} \mathrm{y}+\mathrm{R}) \times 1}
$$


where $\bar{y}$ is the vector of the reference signal, $\lambda_{R} \in \mathfrak{R}^{\mathrm{R}}$ is the penalty term of the $\mathrm{R}^{\text {th }}$ input signal, $\mathrm{u}[\mathrm{n}]$ is the vector of the candidate control signal and $\Delta \mathrm{u}[\mathrm{n}]=\mathrm{u}[\mathrm{n}]-\mathrm{u}[\mathrm{n}-1]$. When the discrete-time nonlinear MPC approach in a MIMO system is considered as an optimization problem, the cost function $\mathrm{F}$ can be formulated as

$$
\mathrm{F}(\mathrm{u}[\mathrm{n}])=\frac{1}{2} \sum_{\mathrm{p}=1}^{\mathrm{K}_{\mathrm{y}}} \sum_{\mathrm{j}=1}^{\mathrm{Q}}\left(\overline{\mathrm{y}}_{\mathrm{j}}[\mathrm{n}+\mathrm{p}]-\hat{\mathrm{y}}_{\mathrm{j}}[\mathrm{n}+\mathrm{p}]\right)^{2}+\sum_{\mathrm{r}=1}^{\mathrm{R}} \frac{1}{2} \lambda_{\mathrm{r}}\left(\mathrm{u}_{\mathrm{r}}[\mathrm{n}]-\mathrm{u}_{\mathrm{r}}[\mathrm{n}-1]\right)^{2}
$$

If a correction term $\sigma_{\mathrm{u}}[\mathrm{n}]$ is added to candidate control signal $\left(\mathrm{u}[\mathrm{n}]+\sigma_{\mathrm{u}}[\mathrm{n}]\right)$, the condition $\mathrm{F}\left(\mathrm{u}[\mathrm{n}]+\sigma_{\mathrm{u}}[\mathrm{n}]\right)<\mathrm{F}(\mathrm{u}[\mathrm{n}])$, which minimizes the cost function with the optimum control signal, is achieved. Finally, $u[n]+\sigma_{u}[n]$ and $\hat{y}_{q}\left[n+K_{y}\right]$ in the MPC structure are the input/output values that specify the amount of irrigation and the amount of water in the soil in the system identification based irrigation model.

\section{Discussions and Future Directions}

For the greenhouses, the control of water content of the soil is relatively easy due to the controlled closed area with continuous measurements. However, the control of irrigation systems belong to the farms is very difficult due to the unknown and unpredictable disturbances from the environment. The main arguments and possible solutions are given as follows.

i) The mathematical model or system identification model of the water content can be assumed true if there are enough measurements are collected and utilized for the construction of the model. However, there exist also limitations since there are no continuous measurements for the years from the same area. To obtain accurate identification model, there is required more data and a bias term to model unknown disturbances affecting to the water content model. Instead of using linear model, a neural network, support vector machine and etc. based irrigation model can be more accurate for the control applications. In addition, an indirect adaptive control method can be used for the unknown disturbances over the water content model. Therefore, the adaptive function approximation model can approximate the all dynamics with disturbance and accurate control results can be provided.

ii) The applied control methods based on the system identification model assume that true predictions exist for the evapotranspiration and precipitation. However, these variables are based on weather conditions and so they are almost random variables. Therefore true predictions are difficult to estimate. There is required very large datasets and accurate time series analysis for the predictions of these variables. Recently, deep learning methods are leading to the prediction and classification works for different fields. Therefore, for the irrigation control system, deep learning based predictions can be used to improve the control of water content in the soil. 


\section{Conclusions}

Irrigation control in the agricultural area has become an important problem due to decreasing water resources. Therefore, water resources should be used efficiently considering the parameters such as soil moisture, temperature, plant root depth, soil texture, water storage capacity of soil, plant water use ability. In this paper, recently applied control methods are surveyed then their advantages and disadvantages are discussed. After that the accurate prediction methods and adaptive control methods are proposed for the future applications when the unknown disturbances affect the dynamics of the soil water content.

\section{Acknowledgements}

This paper is supported by Pamukkale University Scientific Research Projects Council under grand number 2019KRM004-059.

\section{References}

[1] Allen, Richard G., et al. "Crop evapotranspiration-Guidelines for computing crop water requirements-FAO Irrigation and drainage paper 56." Fao, Rome 300.9 (1998): D05109.

[2] Ooi, Su Ki, et al. "A systems engineering approach to viticulture on-farm irrigation." IFAC Proceedings Volumes 41.2 (2008): 9569-9574.

[3] Saleem, Syed Khusro, et al. "Model predictive control for real-time irrigation scheduling." IFAC Proceedings Volumes 46.18 (2013): 299-304.

[4] Delgoda, Dilini, et al. "Irrigation control based on model predictive control (MPC): Formulation of theory and validation using weather forecast data and AQUACROP model." Environmental Modelling \& Software 78 (2016): 40-53.

[5] Shang, C., Chen, W. H., Stroock, A. D., \& You, F. Robust Model Predictive Control of Irrigation Systems With Active Uncertainty Learning and Data Analytics. IEEE Transactions on Control Systems Technology, 2019.

[6] Navarro-Hellín, H., Martínez-del-Rincon, J., Domingo-Miguel, R., Soto-Valles, F., \& Torres-Sánchez, R. A decision support system for managing irrigation in agriculture. Computers and Electronics in Agriculture, 2016, 124, 121-131.

[7] Kim, Y., Evans, R. G., \&Iversen, W. M. Remote sensing and control of an irrigation system using a distributed wireless sensor network. IEEE transactions on instrumentation and measurement, 2008, 57(7), 1379-1387.

[8] Dukes, M. D., \& Perry, C. Uniformity testing of variable-rate center pivot irrigation control systems. Precision Agriculture, 2006, 7(3), 205.

[9] Lopes, S. O., Pereira, R. M., Pereira, P. A., Caldeira, A. C., \& Fonte, V. F. (2019). Optimal control applied to an irrigation planning problem: a real case study in portugal. International Journal of Hydrology Science and Technology, 9(2), 173-188.

[10] Jihin, R., Kögler, F., \& Söffker, D. Data Driven State Machine Model for Industry 4.0 Lifetime Modeling and Identification of Irrigation Control Parameters. In 2019 Global IoT Summit, 2019.

[11] Delgoda, D., Malano, H., Saleem, S. K., \& Halgamuge, M. N. Irrigation control based on 
model predictive control (MPC): Formulation of theory and validation using weather forecast data and AQUACROP model. Environmental Modelling \& Software, 2016, 78, 40-53.

[12] Lozoya, C., Mendoza, C., Mejía, L., Quintana, J., Mendoza, G., Bustillos, M., \& Solís, L. Model predictive control for closed-loop irrigation. IFAC Proceedings Volumes, 2014, 47(3), 4429-4434.

[13] Kia, P. Javadi, et al. "Intelligent control based fuzzy logic for automation of greenhouse irrigation system and evaluation in relation to conventional systems." World Applied Sciences Journal 6.1 (2009): 16-23.

[14] Bahat, M., Inbar, G., Yaniv, O., \& Schneider, M. A fuzzy irrigation controller system. Engineering Applications of Artificial Intelligence, 2000, 13(2), 137-145.

[15] Raju, K. S., \& Kumar, D. N., Fuzzy multi criterion decision making in irrigation planning. Irrigation and Drainage: The journal of the International Commission on Irrigation and Drainage, 2005; 54(4), 455-465.

[16] Mohapatra, A. G., Lenka, S. K., \& Keswani, B. Neural network and fuzzy logic based smart DSS model for irrigation notification and control in precision agriculture. Proceedings of the National Academy of Sciences, India Section A: Physical Sciences, 2019, 89(1), 67-76.

[17] Lee, C. C. Fuzzy logic in control systems: fuzzy logic controller. II. IEEE Transactions on systems, man, and cybernetics, 1990, 20(2), 419-435.

[18] Qiuming, K., Yandong, Z., \& Chenxiang, B. Automatic monitor and control system of water saving irrigation. Transactions of the Chinese Society of Agricultural Engineering, 2007, (6).

[19] Coates, R. W., Delwiche, M. J., Broad, A., \& Holler, M. Wireless sensor network with irrigation valve control. Computers and electronics in agriculture, 2013, 96, 13-22.

[20] Gutiérrez, J., Villa-Medina, J. F., Nieto-Garibay, A., \& Porta-Gándara, M. Á. Automated irrigation system using a wireless sensor network and GPRS module. IEEE transactions on instrumentation and measurement, 2013, 63(1), 166-176.

[21] Wang, L. X. Stable adaptive fuzzy control of nonlinear systems. IEEE Transactions on fuzzy systems, 1993, 1(2), 146-155.

[22] Beyhan, S., Lendek, Z., Babuška, R., Wisse, M., \&Alc1, M. Adaptive fuzzy and slidingmode control of a robot manipulator with varying payload. 50th IEEE Conference on Decision and Control and European Control Conference, 2011,(pp. 8291-8296).

[23] Wang, L. X., A course in fuzzy systems and control (Vol. 2). UpperSaddleRiver, NJ: Prentice Hall PTR, 1997.

[24] Åström, K. J., \&Hägglund, T. PID controllers: theory, design, and tuning (Vol. 2). Research Triangle Park, NC: Instrument society of America, 1995.

[25] Ang, K. H., Chong, G., \& Li, Y. PID controls system analysis, design, and technology. IEEE transactions on control systems technology, 2005, 13(4), 559-576. 